\title{
Co-combustion of solid biomass in pulverized anthracite-coal firing boilers
}

\section{Nataliia Dunaievska, Mykola Chernyavskiy, Taras Shchudlo}

\author{
Coal Energy Technology Institute, Kyiv, Ukraine
}

Keywords:

Co-combustion

Biomass

Coal

Anthracite

\section{Article history:}

Received 12.09.2016

Received in revised

form 24.11.2016

Accepted 27.12.2016

\section{Corresponding author:}

Taras Shchudlo

E-mail:

tarry@ukr.net

DOI: $10.24263 / 2304-$

974X-2016-5-4-14

\section{Abstract}

Introduction. Combustion of solid biomass as a mix with domestic coal in exsisting industrial and utility boilers can not only reduce harmful emissions but also diversifies the generations' fuel base. It also allows effective utilization of solid food processing wastes which otherwise would be dumped and thus cause a strong unfavorable environmental impact.

Materials and method. The pulverized pine-sawdust and anthracite co-combustion has been carried out in down fired experimental unit at $30 \mathrm{~kg} / \mathrm{h}$ fuel rate. The kinetics of the pine sawdust cokes' termal degradation has been studied in fluidized bed unit. The thermal decomposition kinetics of pine wood and straw pellets of wheat, rape, corn and soy were studied by thermogravimetric (TG) method.

Result ans discussion. The co-combustion of pulverized domestic anthracite and wood in the unit VGP-100V has proven its technical realizability and a noticeable potential to significantly improve the quality of low-reactive anthracite combustion. As a result the optimum share of solid biomass of approximately $10 \%$ has been determined. This share allows the stabilization of flame without natural gas addition along with the highest level of fuel carbon conversion.

The internal kinetic mode of pine cokes' samples' combustion was determined for particles size $0,1-1,6 \mathrm{~mm}$ in temperatures' range of $390-560{ }^{\circ} \mathrm{C}$ at the fluidized bed unit RSK-1D.

Some stages of organic biomass thermal decomposition (namely demoisturization, devolatilization and coke burn out) and their kinetics have been detected by means of TG methods. Comparison of pine sawdust and wheat straw pellets' devolatilization kinetics with those available in literature sources indicates that the existing minor deviations may be explained by the difference in sample heating rate, size of sample particles, variation in organic and mineral composition of samples, methods of reaction constants calculation and interpretation. At the same time, the kinetic constants of the devolatilization stage for pellets of different crops straw examined in the present work turned out to be close enough.

Conclusion. Presented results can be used in calculations of the some stages co-combustion processes which take place in TPP's. 


\section{Introduction}

The technology of the biomass as supplementary fuel together coal combustion (BCC technology) has widely spread in the last decades. At present, in Europe o more than 200 boiler units are operated following such technology. A variety of solid biomass is being used. For example, straw as a supplementary fuel is utilized in pulverized coal (PC) boilers (TPP Studstrup, Denmark), wood wastes (TPP Kimiyarvi, Finland), sorted municipal solid wastes (so-called RDF - TPP Lakhti, Finland), crushed bones of olives and other horticultural crops ( TPP Puertolano, Spain), pellets of different agricultural wastes (TPP Drax, Great Britain, TPP Kozenice, Poland) and many other foreign TPP's and CHP's $[1,2]$. The main advantages of the solid biomass and coal co-combustion technology (BCCC) over individual biomass combustion in special dedicated boilers are as follows:

- Minimal capital investments, since biomass combustion takes place in already existing boilers and needs the construction of only plants of biomass reception, on site transportation and pre-combustion preparation;

- Reduction of pollutant emissions since biomass is considered as $\mathrm{CO}_{2}$-neutral fuel, has much lower (in comparison with domestic coal) content of sulphur nitrogen compounds;

- Prospective to reduce thermal and electric generation due to fossil fuel;

- Significant potential to recycle wastes of different production types and thereby reduce the environmental pollution;

- Growing feasibility of biomass using in coal boiler units under appropriate legislation (the "green tariff", the fee for biomass dumping in landfills, etc.).

The said technology has so far been implemented in a variety of arrangements, as follows [1]:

- in PC boiler units;

- in CFB boilers;

- the biomass gasification in separate gasifiers with subsequent burning in coal boilers.

As per environmental performances of the co-combustion process, the abovementioned sulphur oxide reduction can be noted due to lower content of such substance in the biomass, its $\mathrm{CO}_{2}$ - neutrality in combustion processes, experimental data on nitrogen oxide reduction are in many foreign editions $[3,4,5]$.

The $\mathrm{NO}_{\mathrm{x}}$ reduction can be explained by technological factors, also: a high devolatilization rate of biomass can be explained the creation of enriched fuel zone at the beginning of the torch at the exit of the burner. A high moisture content of some biomasses could also effect on nitrogen oxide reduction in boiler furnace.

It should be noted that just a few domestic works addressed the problems of the dynamics of biomass dehydration and devolitalization. In works [6,7] the set of equations for the calculating kinetic constants has been proposed. Particularly, the equation [6] allow to calculate the time span of the dehydration and devolatilization stages of complex process of certain types of biomass combustion. At the same time it is clear that the data avaliable in literature are insufficient and lacking fist of all the kinetic characteristics of biomass mixtures combustion and biomass cokes burned out.

The BCC technology combustion of such heterogeneous fuel as anthracite and plant solid biomass is of particular interest. A small part only of volume of the total world BCC technology studies is devoted to these fuels, mostly the studies of scientists are from those regions where anthracite is mined (in general - $5 \%$ of the world's deposits explored). These 


\section{— Processes and Equipment of Food Productions -}

are the countries, such as: Korea, Vietnam, South Africa, Spain and Pennsylvania State in the USA.

Currently, the irregular supply of the anthracite from the occupied territories of the Donetsk coal basin is typical for Ukraine. For instance, in 2015 compared to 2013 the supply of the anthracite (rank A and T) at TPP's reduced from 18 to 8 million tons taking into account the supplies from Russia and Republic of South Africa. At the same time, the market of biomass as fuel is rapidly growing (the pellet plants that were built for the money of foreign grants and investors). The displacement at least of the anthracite part for the biomass is a partial solution of the critical situation that led to boiler units' shutdown of Zmiyevska and Trypilska TPP's this winter.

The CETI almost for 10 years has been working on the biomass and anthracite cocombustion technology development, the beginning of which founded a joint project with Pittsburgh Energy Technology Center (PETC) of the Ministry of Energy of the USA under the NATO Program "Science for Peace" since 2007. In the course of works, the optimum regime characteristics, the synergetic effects of the mutual influence of two different solid fuels, the kinetic characteristics of the pine sawdust for combustion process calculation, defined $[8,9]$. The purposes of the studies were the following:

- to identify the optimum biomass/anthracite ratio for the most complete burnout of both fuels at residence time in the anthracite PC boiler furnace;

- to determine the optimal performance characteristics of such combustion;

- to determine the characteristics of a wide range of the domestic biomass (pine sawdust, pulp, pellet of wheat straw, rape, etc.) for the BCCC calculation;

- to investigate the effect of the biomass impurities on coal burnout efficiency;

- to study the effect of the biomass impurities on environmental performances of the mixture burnout;

- based on experimental and theoretical studies, to develop the burners' and primary furnaces' constructions for combustion as separately biomass as its mixtures with coal.

\section{Materials and methods}

The BCC experiments were conducted at the pilot unit VGP-100V which simulate the processes that take place in the lower radiation part of boiler furnace. The aim of pilot cocombustion was to confirm the possibility of natural gas, injected for torch "lighting", substitution by volatiles of biomass. Here the biomass with a high volatile content is supposed to offset the deficiency of volatiles in coal, betters torch ignition, provides its stability when firing high-ash low-reactive anthracite,

The principal schematics of the pilot unit VGP-100V (thermal output up to $100 \mathrm{~kW}$ in the mode of coal combustion in raw air) is shown on Figure 1. It includes the vertical downstream reactor 1 , the burner 2 , the slag bath 3 , the turning area with cyclone 4 , the cooling and afterburn chamber 5 . The total length of the reactor is $4,8 \mathrm{~m}$, the reactor area to the turn into a cyclone is $3,2 \mathrm{~m}$; the length of the diagnostic area from the original section of the burner is $2,4 \mathrm{~m}$.

The diagnostic area consists of 4 sections length of $0,6 \mathrm{~m}$, the internal diameter is 0,28 $\mathrm{m}$ (the diameter of the rest channel to turn is $0,2 \mathrm{~m}$ ). The water-cooling walls of the reactor are covered with the three-layer lining from the inside: the fire layer - zirconium dioxide, the heat-insulation layer - chamotte, the strain isolation layer - asbestos fabric. 


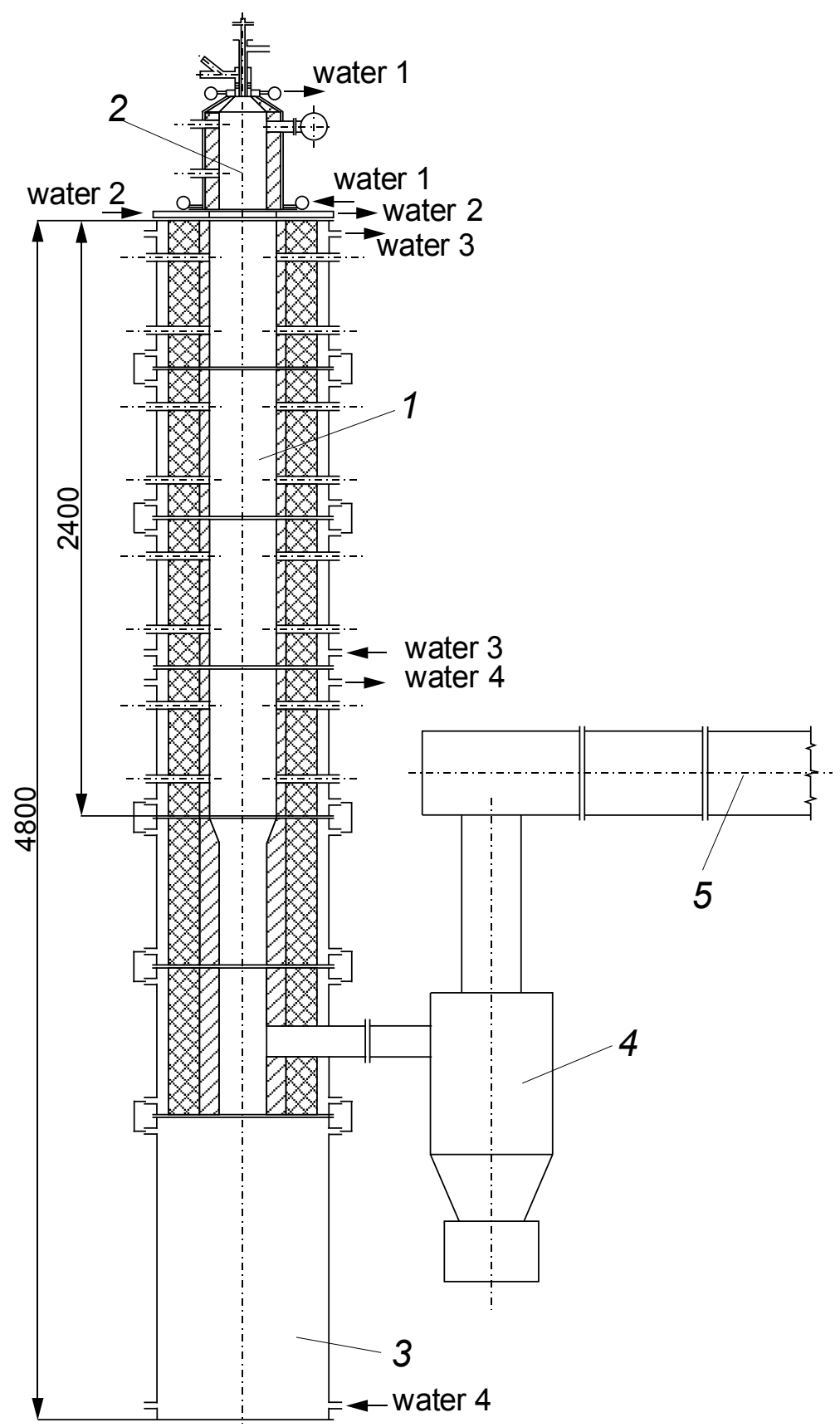

Figure 1. Experimental unit VGP-100V 


\section{— Processes and Equipment of Food Productions -}

The burner is vertical water-cooling lined cylinder with internal diameter of $0,2 \mathrm{~m}$, length of $0,5 \mathrm{~m}$, installed through water-cooling transition flange on the upper section of the reactor, equipped with two burners and operational and diagnostic windows.

From its end the primary gas burner is installed and designed for combustion of the natural gas, sawdust or its mixture. The natural gas duct is coaxially located to main gas burner which ends short section with perforation for gas release. The air or air/sawdust mixture supply duct is coaxially located to gas duct which ends vane swirler to intensify air blowing with gas and sawdust - with combustible products.

The auxiliary gas burner with electroignition that is differed by air walls' air-cooling with heated air supply to the burner, is installed on the side wall of the burner.

The supply of the following reagents is foreseen, such as:

- the natural gas - in the main and auxiliary burners;

- the air - in the main and auxiliary burners, transporting air with coal and sawdust, secondary air;

- the coal - in the upper part of the burner through the side wall;

- the biomass - in the primary burner.

The unit is equipped with two independent measuring devices: the coal measuring device - the productive efficiency from 5 to $40 \mathrm{~kg}$ per hour and the sawdust measuring device - the productive efficiency from 3 to $15 \mathrm{~kg}$ per hour.

The experiments are controlled:

- the natural gas and air consumption behind each of the input channels - by the rotameters;

- the sawdust consumption - following the calibration chart of voltage on windings of the motor and following the pressure in front of the ejector;

- the coal dust consumption - following the calibration chart of voltage on windings of the motor;

- the lining temperature on the reactor length - by two-spectral pyrometer "DPR-1" (the fire layer, at times) and K-type thermocouples immersed in the lining layer over 5-10 $\mathrm{mm}$ from fire surface (always);

- the gas flow temperature - by the S-type thermocouples embedded to axis of the channel;

- the rarefaction in the reaction zone - by the U-shaped sensor;

- the composition of combustible products at reactor output - by gas analyzers: by massspectrometer MX-1215 and portative gas analyzer MRU Vario Plus.

The indications of the K-type thermocouples and mass-spectrometer are processed from analog to digital signals, displayed on monitor screen for operational control (updating each $0,5 \mathrm{~s}$ ) and registered (each $20 \mathrm{~s}$ ) by automated control system on the basis of PC. The gas phase analysis is constantly taken off at the reactor outlet by water cooling sampling probe, the probe transporting time (constant time delay) to gas analyzer no more than $15 \mathrm{~s}$. At $\mathrm{T}_{\text {reactor }}=1200-1250^{\circ} \mathrm{C}$, the residence time $\tau$ was at the level of $0,75-0,8 \mathrm{~s}$ which is close to residence time of particles in the lower radiation part of the pulverized boilers' furnace.

\section{The kinetic studies of dehydration, devolatilization and cokes' burning of different biomass types}

The above-mentioned studies of the BCC processes examined with use of wood that is considered one of the most environmental types of the solid biomass available in Ukraine. 


\section{— Processes and Equipment of Food Productions -}

However, due to high demand on the wood and its wastes in wood processing and other industries, the shortage for this type of biomass as fuel could take place in some regions of Ukraine. At the same time, there is a large number of available straw of different crops in the country that is also used in the world in the BCCC technology but not so prevalent because of high chlorine content in it, which has a negative impact as on the state of the boiler heating surface as on environmental friendliness of its operation. In the event of chlorine problem solution in the future, the biomass number for a large-scale BCCC technology implementation is significantly expanded. Therefore, to determine the possibility of straw using of the different crops available in Ukraine for co-combustion technology, in cooperation with the Ural Federal University (the Yekaterinburg city, Russia) and the Institute of Macromolecular Chemistry of NAS of Ukraine (the Kyiv city) were held the thermogravimetric studies of the wheat straw, canola, corn and soybeans' pellets' samples, and for comparison, samples of wood (sawdust), which used in previous studies on panels of the CETI of NAS. The pellet samples' studies conducted on derivatograph of the Paulik-Paulik-Erdey Q-1000 system in air atmosphere with heating rate of $20^{\circ} \mathrm{C} / \mathrm{min}$. in temperature range of Tambient $-1000{ }^{\circ} \mathrm{C}$. The mass of test samples was $100 \mathrm{mg}$. The wood samples studied at integrated complex of simultaneous thermal analysis STA 449 Jupiter by NETZSCH company in air atmosphere with heating rate of $5{ }^{\circ} \mathrm{C} / \mathrm{min}$. in temperature range of Tambient $-700{ }^{\circ} \mathrm{C}$.

\section{The kinetic studies of the wood cokes' burning at unit RSK-1D}

To calculate the next biomass combustion in the upper part of the boiler furnace it is necessary to determine the kinetic characteristics of the biomass coke burning. Despite the fact that during the wood combustion, the volatile yield is $80-85 \%$, the burnout time of just biomass coke residue determines the total time required for combustion of fuel mixture. Therefore, to clarify the characteristics of the wood coke burnout, the kinetic studies at unit RSK-1D of the Coal Energy Technology Institute (CETI) were held, that is a vertical pulse gradientless fluidized bed reactor.

The unit RSK-1D (Figure 2) is designed to study the kinetics interaction with gasesreagents at temperature up to $1250{ }^{\circ} \mathrm{C}$. It is a differential pulse reactor that operates in modes near to ideal elimination in gas phase and ideal mixing in solid phase, as well as allows to support small temperature gradients (less than $10 \mathrm{~K}$ ) in the reaction zone along the height mounting under performance of the experiments.

The intensive fuel particles' blending provides the mode of ideal mixing in solid phase and also almost the uniform concentration of the gas-reagent in the sample layer. The gas flow in the reactor promotes the ideal elimination mode in gas-reagent pulse.

The base of the unit (Figure 2) is vertical tube furnace with one-through cylindrical reactor located inside and manufactured of heat-resistant steel (height $1,1 \mathrm{~m}$, internal diameter $3,3 \mathrm{~cm}$ ). At the bottom of the reactor is inert magnesium oxide filling intended for gas-reagent heating that is supplied from the bottom, on the top of which the fluidized air distribution grate is located. The grate is made of fine-mesh ceramics and has a resistance of $1000 \mathrm{~Pa}$ due to which an equal distribution of the gas-reagent flow rates in cross section of the reactor is achieved. The temperature in the reaction zone is controlled by K-type thermocouples located in the centre of the fluidized volume of the coke sample examined, in furnace and outside of the reactor (all at one level). The temperature measurement is 
provided by multichannel analogue/digital converter (ADC UKT-38). The gases' supply is made by means of gas conditioning - air and helium bottle batteries (argon, nitrogen).

During the kinetic experiment carrying out the gas flow passing through reactor, is measured. The gas components' concentrations are measured by gas analyzer Siemens Utramat 23.

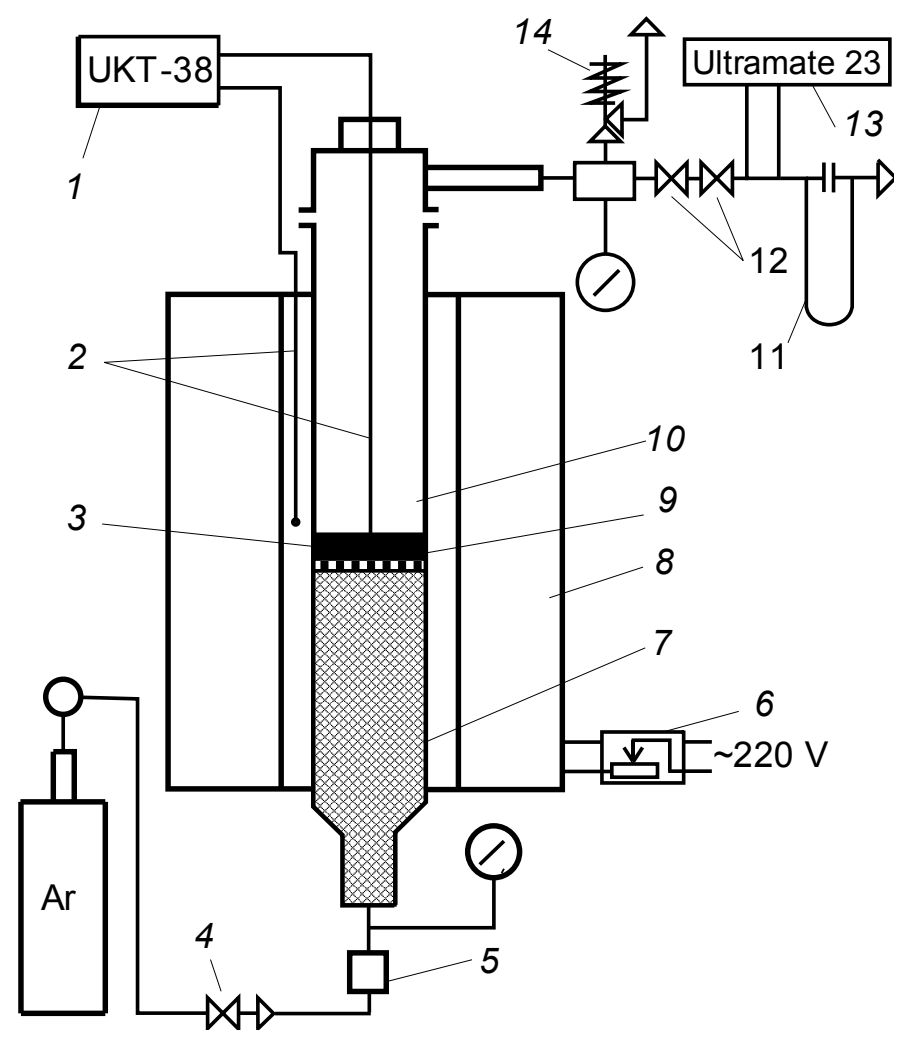

Figure 2. Unit RSK-1D:

1 - ADC; 2 - thermocouples; 3 - timber weight; 4 - needle valves; 5 -dosing device; 6 - voltage regulator; 7 - magnesium oxide filling; 8 - tube furnace; 9 - perforated grate;

10 - reactor; 11 - flowmeter; 12 - needle valve; 13 - gas analyzer; 14 - explosive valve.

At the beginning of the experiment, the dependence $R_{m}=f(T)$ is read step by step (in $10^{\circ} \mathrm{C}$ ). The pulse input is made no more than two times at each temperature level.

Upon receipt of the rate dependencies from the temperature, the gas-reagent pulse value chosen so as to the reduction of the carbon mass $D_{m}$ in timber weight was much less its initial value $\mathrm{m}_{\mathrm{o}}$, and based on the marginal sensitivity of the gas analyzer used and compliance with isothermality conditions in the reaction zone. During the kinetic studies, the gas-reagent pulse value that is given by loop volume, was chosen experimentally.

The technical analysis of fuels examined at unit VGP-100V, derivatograph Q-1000 and unit RSK-1D are shown on Table 1. 
Table 1

\begin{tabular}{|l|c|c|c|c|}
\hline Sample & $\mathrm{W}^{\mathrm{r}}, \%$ & $\mathrm{~A}^{\mathrm{d}} \% \%$ & $\mathrm{~V}^{\mathrm{d}}, \%$ & $\mathrm{~V}^{\text {daf }}, \%$ \\
\hline unthracite №1 & 1,1 & 24,8 & 5,5 & 7,3 \\
\hline Anthracite №2 & 0,6 & 27,9 & 5,3 & 7,3 \\
\hline Pine sawdust & 10,0 & 1,8 & 83,5 & 85,0 \\
\hline \multicolumn{5}{|c|}{ derivatograph Q-1000 } \\
\hline Pine sawdust 1 & 8,3 & 2,9 & 82,93 & 85,41 \\
\hline Pine sawdust 2 & 10 & 0,9 & 83,06 & 83,81 \\
\hline Wheat straw pellets & 9,2 & 8,9 & 74,52 & 81,80 \\
\hline Rape pellets & 9,6 & 11,2 & 73,08 & 82,30 \\
\hline Corn pellets & 10,6 & 15,0 & 70,55 & 83,00 \\
\hline Soy beans pellets & 11,4 & 11,8 & 73,82 & 83,70 \\
\hline \multicolumn{5}{|c|}{ unit RSK-1D } \\
\hline Pine sawdust & - & 1,75 & 80,85 & 82,3 \\
\hline
\end{tabular}

\section{Results and discussion}

The primary experimental data from derivatograph Q-1000 obtained in the form of electronic tables and in graphic form, also. The data include curves of mass and temperature changes, rate of mass change, rate of temperature change during the experiment. Conventionally, it can be separated on stage of dehydration, formation and release of volatiles and coke-ash residue burning. To determine the temperature limits of the each stage of the fuel samples thermal decomposition, the initial temperature $T_{0}$ where the sample weight is 0,975 from the original and the maximal temperature of the stage $T_{\max }$ which the second derivative from the mass change is zero and the final temperature of the stage where the first derivative from the mass change has a minimal value and the second is zero, are defined.

The following kinetic equation of each stage of thermal decomposition is considered [10]:

$$
-\frac{d \alpha}{d \tau}=k \cdot f(\alpha)
$$

where $\alpha$ - the degree of the experimental sample conversion shows which part of the experimental sample reacted to the timepoint $\tau ; k$ - the reaction rate constant; $f(\alpha)$ - the function that characterizes the reaction mode. The conversion degree at the timepoint $\tau$ is determined from the derivatogram by the formula $\alpha=\frac{m_{0}-m_{\tau}}{m_{0}-m_{\infty}}$

where $m_{0}$ - the initial sample weight; $m_{\infty}$ - the thermal decomposition final mass; $m_{\tau}$-the current sample mass. To represent the reaction rate constant, the Arrhenius formula is used:

$$
k=k_{0} \exp \left(-\frac{E}{R T}\right)
$$




\section{— Processes and Equipment of Food Productions -}

where $k_{0}$ - pre-exponential factor; $\mathrm{E}$ - energy of activation, $\mathrm{J} / \mathrm{mol} ; \mathrm{R}$ - universal gas constant, $8,314 \mathrm{~J} / \mathrm{mol} \cdot \mathrm{K} ; \mathrm{T}$ - temperature, $\mathrm{K}$.

Combining the equations (1) i (2), we obtain the following form of equation (1):

$$
\frac{d \alpha}{d \tau}=k_{0} \cdot \exp \left(-\frac{E}{R T}\right) \cdot f(\alpha)
$$

To simplify the calculations, the assumption common in thermogravimetric studies was accepted that existing reactions of the thermal decomposition are of the first order. Then, the function $f(\alpha)=(1-\alpha)$ and, as a result, (3), we obtain known differential kinetic equation:

$$
\operatorname{Ln}\left(\frac{1}{1-\alpha} \frac{d \alpha}{d \tau}\right)=-\frac{E}{R T}+\operatorname{Ln}\left(k_{0}\right)
$$

The equation (4) is a linear dependence of the expression $\operatorname{Ln}\left(\frac{1}{1-\alpha} \frac{d \alpha}{d \tau}\right)$ from reciprocal temperature $\frac{1}{T}$ in form of $\mathrm{y}=\mathrm{k} \cdot \mathrm{x}+\mathrm{b}$, where $\mathrm{k}=\left(-\frac{E}{R}\right), \mathrm{a} \mathrm{b}=\operatorname{Ln}\left(k_{0}\right)$.

During the experimental data processing on kinetics of the wood coke burning at unit RSK-1D, the calculations of the specific burning rate and degree of conversion carried out on the basis of the mass flow measurement $\mathrm{CO}$ and $\mathrm{CO}_{2}$ by gross reaction of $\mathrm{C}+\mathrm{O}_{2}: \mathrm{R}_{\mathrm{m}}=$ $(\Delta \mathrm{m} / \Delta \mathrm{t}) / \mathrm{m}$

$\mathrm{R}_{\mathrm{m} 0}=(\Delta \mathrm{m} / \Delta \mathrm{t}) / \mathrm{m}_{0}$;

$(\Delta \mathrm{m} / \Delta \mathrm{t})=\mathrm{M}_{\mathrm{C}} \mathrm{G}_{\mathrm{gas}}\left([\mathrm{CO}]+\left[\mathrm{CO}_{2}\right]\right) / 22.4$, where $\mathrm{m}, \mathrm{m}_{0}$ - the current and initial mass of carbon; $\mathrm{R}_{\mathrm{m}}, \mathrm{R}_{\mathrm{m} 0}$ - the specific carbon burning rate, $\mathrm{kg} /(\mathrm{kg} \cdot \mathrm{s}) ; \Delta \mathrm{m}$ - the carbon mass reduction, $\mathrm{kg} ; \Delta \mathrm{t}$ - the pulse time, $\mathrm{s} ;(\Delta \mathrm{m} / \Delta \mathrm{t})$ - the overall rate of the carbon burn-out in sample, $\mathrm{kg} / \mathrm{s} ; \mathrm{M}_{\mathrm{C}}=12$ - the molar carbon mass, $\mathrm{kg} / \mathrm{kmol} ; \mathrm{G}_{\mathrm{gas}}$ - the total consumption of combustible products at the reactor outlet, $\mathrm{m}^{3} / \mathrm{s}$ (under normal conditions); [CO], [ $\left.\mathrm{CO}_{2}\right]-$ the average during pulse time concentrations $\mathrm{CO}$ и $\mathrm{CO}_{2}$, the percentage (by volume).

The degree of the carbon conversion in pulse $i$ is the expression $X_{i}=R_{m 0} \Delta t$.

The experimental data are accumulated in electronic spreadsheet, the rated elements among others were (for pulse i): $(\Delta \mathrm{m} / \Delta \mathrm{t})_{\mathrm{i}}, \Delta \mathrm{m}_{\mathrm{i}}=\Delta \mathrm{t}(\Delta \mathrm{m} / \Delta \mathrm{t})_{\mathrm{i}}$, where $\mathrm{m}_{\mathrm{i}}=\mathrm{m}_{0}-\left(\Delta \mathrm{m}_{1}+\Delta \mathrm{m}_{2}\right.$ $\left.+\ldots+\Delta \mathrm{m}_{\mathrm{N}-1}\right)-$ the current carbon mass that is not reacted in weight for pulse starting (where $\mathrm{N}$ - the pulse number, $\left.\mathrm{m}_{1}=\mathrm{m}_{0}\right)$; the sample conversion degree $\mathrm{X}_{\mathrm{i}}=1-\left(\mathrm{m}_{\mathrm{i}} / \mathrm{m}_{0}\right)$; the carbon burning specific rates $\left(\mathrm{R}_{\mathrm{m}}\right)_{\mathrm{i}}=(\Delta \mathrm{m} / \Delta \mathrm{t})_{\mathrm{i}} / \mathrm{m}_{\mathrm{i}}$ and $\left(\mathrm{Rm}_{0}\right)_{\mathrm{i}}=(\Delta \mathrm{m} / \Delta \mathrm{t})_{\mathrm{i}} / \mathrm{m}_{0}$. The initial mass $\mathrm{m}_{0}$ of the carbon in weight is determined on the basis of the coke technical analysis. The obtained data were processed in the form of the reaction rate dependence from conversion degree at a given temperature $T\left[R_{m}=f(X)\right.$ at $T=$ const $]$ and reaction rate dependence from temperature $\left[R_{m}=f(T)\right]$.

Following the above-mentioned method, the primary data of derivatograms were processed. The temperature ranges of thermal decomposition individual stages of the biomass samples under examination, as well as distribution of fuel samples' initial mass following thermal conversion stages, are shown in Table 2.

Analyzing the temperature-zero coefficients and its extremes in certain stages of thermal decomposition, the attention is drawn to the proximity of these values for all biomass types explored. However, among others it could be possible to mark pine sawdust 
which due to large release of volatiles has almost $20 \%$ more thermal mass fraction of appropriate thermal stage and less mass of the coke residue. Moreover, the temperature ranges of the sawdust sample dehydration stage are shorter for $34-78{ }^{\circ} \mathrm{C}$ compared to other samples.

The pre-exponential factor calculation results $\left(\mathrm{k}_{0}\right)$ and activation energy (E) for dehydration and devolatilization stages of the fuel samples studied, as well as similar research data from sources of literature, are shown in Table 3.

Table 2

Temperature ranges and mass distribution of thermal decomposition individual stages of biomass samples

\begin{tabular}{|c|c|c|c|c|c|c|c|c|c|}
\hline \multirow[b]{3}{*}{ Fuel sample } & \multicolumn{9}{|c|}{ Fuel thermal decomposition stage } \\
\hline & \multicolumn{3}{|c|}{ dehydration } & \multicolumn{3}{|c|}{ devolatilization } & \multicolumn{3}{|c|}{ Coke residue burn-out } \\
\hline & 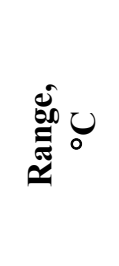 & 志 & 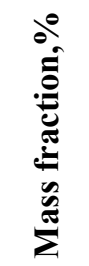 & 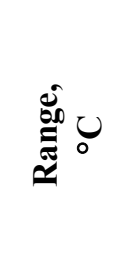 & 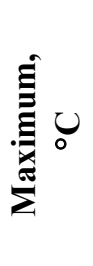 & 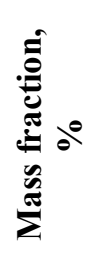 & 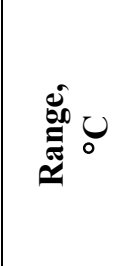 & 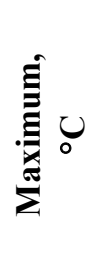 & 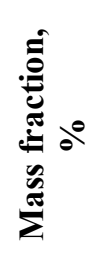 \\
\hline $\begin{array}{l}\text { Pine sawdust } \\
1\end{array}$ & $27-120$ & 65 & 7,20 & $120-416$ & 301 & 79,80 & $416-697$ & $\mathrm{n} / \mathrm{s}$ & 13,00 \\
\hline Pine sawdust & $32-136$ & 56 & 6,80 & $136-404$ & 307 & 77,20 & $404-610$ & $\mathrm{n} / \mathrm{s}$ & 16,00 \\
\hline $\begin{array}{l}\text { Wheat straw } \\
\text { pellets }\end{array}$ & $24-187$ & 100 & 6,18 & $187-440$ & 290 & 62,60 & $440-920$ & $\mathrm{n} / \mathrm{s}$ & 31,19 \\
\hline Rape pellets & $23-194$ & 103 & 9,54 & $194-418$ & 303 & 57,98 & $418-872$ & $\mathrm{n} / \mathrm{s}$ & 32,32 \\
\hline Corn pellets & $24-186$ & 99 & 9,44 & $186-416$ & 281 & 58,02 & $416-940$ & $\mathrm{n} / \mathrm{s}$ & 32,51 \\
\hline $\begin{array}{l}\text { Soy beans } \\
\text { pellets }\end{array}$ & $23-161$ & 98 & 9,23 & $161-404$ & 294 & 56,79 & $404-898$ & $\mathrm{n} / \mathrm{s}$ & 33,89 \\
\hline
\end{tabular}

$\mathrm{n} / \mathrm{s}-$ not specified

The graphical dependence of the devolatilization rate from reciprocal temperature in acc. to equation (4) for solid biomass samples studied is shown on Figure 3.

From the Figure, we can see a significant difference in devolatilization rate from the wood compared to other straw pellet samples studied, which can be explained by differences in nature of the above-mentioned crops growth, somewhat different heating rate during the study, as well as different step of its previous processing. Compared the pine sawdust samples and wheat straw pellets' results received during the study with results obtained in foreign studies [6,11-14] (Table 3), mainly we see the difference in devolatilization rate that is explained by discrepancy in heating rate of samples during the experiment, different grinding degree of samples studied, difference in organic and mineral composition of samples due to different growth and storage conditions, difference in approaches to calculate reaction constants. Instead, the devolatilization rate values' proximity of the straw pellets' samples of the different crops in the given study that were obtained under the same conditions and at the same facilities, is observed. 
Table 3

The pre-exponential factor $\left(k_{0}\right)$ and activation energy $(E)$ calculation results for stages of dehydration and devolatilization of fuel samples studied and its literature analogues

\begin{tabular}{|c|c|c|c|c|c|}
\hline \multirow{3}{*}{ Fuel sample } & \multirow{3}{*}{$\begin{array}{c}\text { Heating } \\
\text { rate, } \\
{ }^{\circ} \mathrm{C} / \mathrm{min} .\end{array}$} & \multicolumn{4}{|c|}{ Fuel thermal decomposition stage } \\
\hline & & \multicolumn{2}{|c|}{ dehydration } & \multicolumn{2}{|c|}{ devolatilization } \\
\hline & & $\mathbf{k}_{\mathbf{0}}, \mathbf{1} / \mathbf{s}$ & $\mathrm{E}, \mathrm{kJ} / \mathrm{mol}$ & $\mathbf{k}_{\mathbf{0}}, \mathbf{1} / \mathbf{s}$ & $\mathrm{E}, \mathrm{kJ} / \mathrm{mol}$ \\
\hline Pine sawdust 1 & 5 & 4373,85 & 39,19 & 80,02 & 54,76 \\
\hline Pine sawdust 2 & 5 & 1018,31 & 35,02 & 2627,79 & 71,34 \\
\hline Wheat straw pellets & 20 & 1,51 & 16,35 & 177,03 & 52,15 \\
\hline Rape pellets & 20 & 8,90 & 22,82 & 472,72 & 55,58 \\
\hline Corn pellets & 20 & 13,18 & 23,32 & 2145,44 & 63,11 \\
\hline Soy beans pellets & 20 & 443,86 & 33,78 & 740,19 & 56,57 \\
\hline Тирса сосни [11] & 15 & - & - & $6,60 \cdot 10^{8}$ & 102,30 \\
\hline Pine [12] & 10 & - & - & $7,32 \cdot 10^{7}$ & 122,56 \\
\hline Pine sawdust [6] & 20 & 13,60 & 24,52 & 164400 & 87,37 \\
\hline Wheat straw [13] & 30 & - & - & $2,61 \cdot 10^{8}$ & 115,59 \\
\hline Wheat straw [6] & 20 & 13,70 & 25,85 & 92470 & 82,00 \\
\hline Soy beans [14] & $5-20$ & - & - & - & 182,00 \\
\hline
\end{tabular}

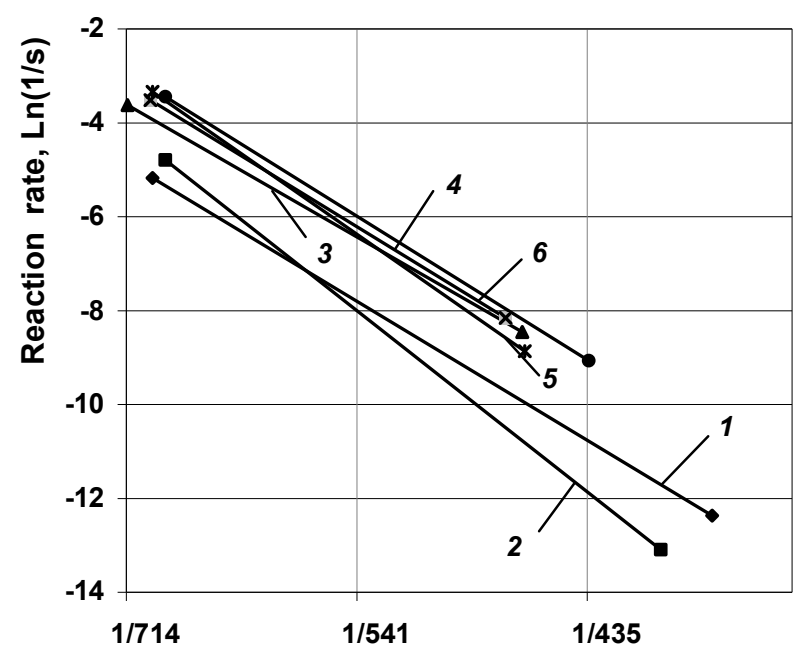

Inverse temperature, $1 / \mathrm{K}$

Figure 3. Comparison of the volatile yield rate dependencies from pine sawdust and pellets' sample reciprocal temperature studied, where 1 and 2 - pine sawdust as per 1 and 2,3 - wheat straw pellets, 4 - rape straw pellets, 5 - corn straw pellets, 6 - soy straw pellets 


\section{— Processes and Equipment of Food Productions -}

The studies' results at the unit RSK-1D to determine the carbon burn-out specific rate dependence of wood coke (fraction size 0,1-1,6 mm) from inverse temperature (the temperature range of $390-560{ }^{\circ} \mathrm{C}$ in the study), which were obtained following the abovementioned approach, are shown on Figure 4 in semilog coordinates. As can be seen from the graph, in temperature range studied, the wood coke particle size, as well as gas-reagent rate change in the reactor does not affect the ambient oxygen interaction rate which indicate the presence of intra-kinetic burning regime of the samples studied in the temperature range of $390-560^{\circ} \mathrm{C}$.

Analyzing the linear dependence obtained for wood cokes following the abovementioned approach, we get the rate constant of the reaction $\mathrm{K}_{\mathrm{ol}}=4,9 \cdot 10^{4}[1 / \mathrm{s}] /\left[\mathrm{kg} / \mathrm{m}^{3}\right]$ and activation energy $E=199,3 \mathrm{~kJ} / \mathrm{mol}$. As the study of the specific surface area of the wood coke particles has not been conducted, the $\mathrm{K}_{\mathrm{oII}}$ constant value was not measured.

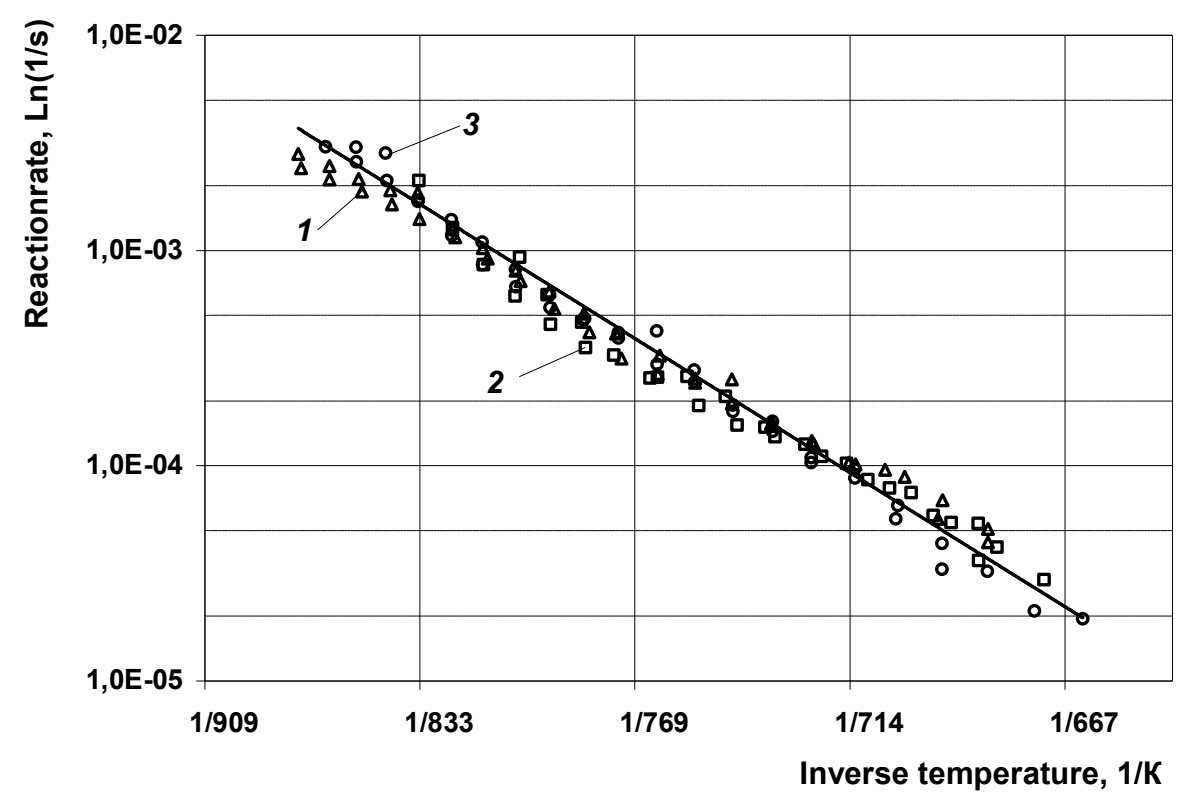

Figure 4. The dependence of the wood coke carbon burn-out rate from inverse temperature $\left(\mathrm{T}=390-560{ }^{\circ} \mathrm{C}\right): 1$ - coke 0,1-0,2 mm; 2 - coke 0,4-0,5 mm; 1 - coke 1,25-1,6 mm;

The BCCC experiments at unit VGP-100V conducted using natural gas both to simulate the thermal input of the hot air the temperature of which at TPPs of Ukraine reaches $400{ }^{\circ} \mathrm{C}$ (for anthracite burning), as to compare the effect of gas (under "lighting") and biomass (under co-combustion) for the coal burnout process.

The Table 4 shows the summary experiments' results at unit VGP-100V. The coal carbon conversion degree during the coal/natural gas co-combustion depends on coal ash content and gas share for "lighting". The degree of common influence of such factors could be changed depending on specific combination of the process parameters. Thus, under gas consumption that provided steady burning, the further increase of its consumption under other identical process parameters reduces the carbon conversion degree that confirmed by regimes 1 and 4. For coal of even ash content in conditions of the gas consumption increase 
(by heat rate) from 6,9 to $20,8 \%$, the conversion degree is reduced from 63,4 to $52,3 \%$ that is explained by intense oxygen absorption under combustion of more reactive gas with lower temperature ignition.

The experiments conducted of the biomass and anthracite (of different ash content) cocombustion are shown in Table 4 (regimes 6-8). In the experiments, the biomass portion (that is burnt) is varied in appropriate range of heat portion introduced within 2,9-13,9\% taking into account heat expended for air heating. The anthracite carbon conversion degree under its co-combustion with biomass, is determined based on consideration of reference value of the biomass conversion degree when it is burning with gas, which was obtained during the separate regime of combustion. Based on the values of the anthracite carbon conversion degree found in this way, it is possible to determine the optimal sawdust share which provides the torch stability along with maximal carbon conversion degree.

Table 4

The experimental regime characteristics

\begin{tabular}{|c|c|c|c|c|c|c|c|c|c|c|c|c|c|c|}
\hline \multirow{2}{*}{$\begin{array}{l}\stackrel{0}{\Xi} \\
\stackrel{0}{0} \\
\widetilde{\Xi}\end{array}$} & \multirow{2}{*}{ 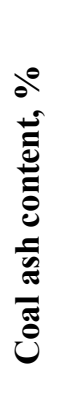 } & \multicolumn{2}{|c|}{$\begin{array}{c}\text { Conversion } \\
\text { degree, } \%\end{array}$} & \multirow{2}{*}{ 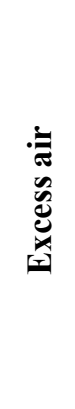 } & \multirow{2}{*}{ 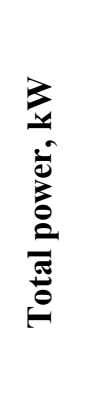 } & \multirow{2}{*}{ 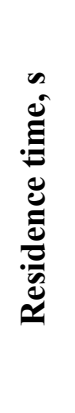 } & \multicolumn{4}{|c|}{$\begin{array}{l}\text { Gas temperature in } \\
\text { sections, }{ }^{\circ} \mathrm{C}\end{array}$} & \multicolumn{4}{|c|}{$\begin{array}{l}\text { Fuel share under } \\
\text { heat, } \%\end{array}$} \\
\hline & & 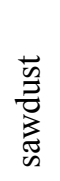 & ర్ర & & & & 1 & 2 & 3 & 4 & $\overbrace{0}^{2}$ & 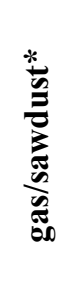 & ฮี & 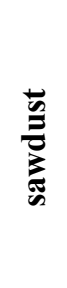 \\
\hline \multicolumn{15}{|c|}{ Natural gas and coal combustion } \\
\hline 1 & 24,8 & 0 & 63,4 & 0,74 & 146,6 & 0,9 & 1340 & 1340 & 1330 & 1200 & 11,3 & 6,9 & 88,7 & 0 \\
\hline 2 & 27,9 & 0 & 60,8 & 0,76 & 141,4 & 0,9 & 1300 & 1350 & 1355 & 1250 & 11,7 & 7,2 & 88,3 & 0 \\
\hline 3 & 24,8 & 0 & 59,2 & 0,8 & 147,8 & 0,9 & 1002 & 1275 & 1320 & 1202 & 12,0 & 6,5 & 88 & 0 \\
\hline 4 & 27,9 & 0 & 52,3 & 0,82 & 146 & 0,8 & 940 & 1260 & 1380 & 1320 & 25,7 & 20,8 & 74,3 & 0 \\
\hline 5 & 27,9 & 0 & 73,3 & 0,86 & 148,1 & 0,9 & 940 & 1090 & 1100 & 1010 & 26,8 & 20,2 & 73,2 & 0 \\
\hline \multicolumn{15}{|c|}{ Biomass and coal co-combustion } \\
\hline 6 & 24,8 & 80 & 56,5 & 0,47 & 172,9 & 0,8 & 1380 & 1445 & 1405 & 1290 & 0 & 2,9 & 92,9 & 7,1 \\
\hline 7 & 27,9 & 80 & 70,4 & 0,78 & 154,4 & 0,7 & 1445 & 1445 & 1415 & 1305 & 0 & 13,9 & 80,9 & 19,1 \\
\hline 8 & 27,9 & 80 & $\begin{array}{l}75,9 \\
\end{array}$ & 0,85 & 145,7 & 0,7 & 1445 & 1445 & 1405 & 1330 & 0 & 8,4 & 85,7 & 14,3 \\
\hline
\end{tabular}

Notes:

* - the natural gas/sawdust heat share taking into account its consumption for air heating up to $320^{\circ} \mathrm{C}$ at TPP that is operated. 

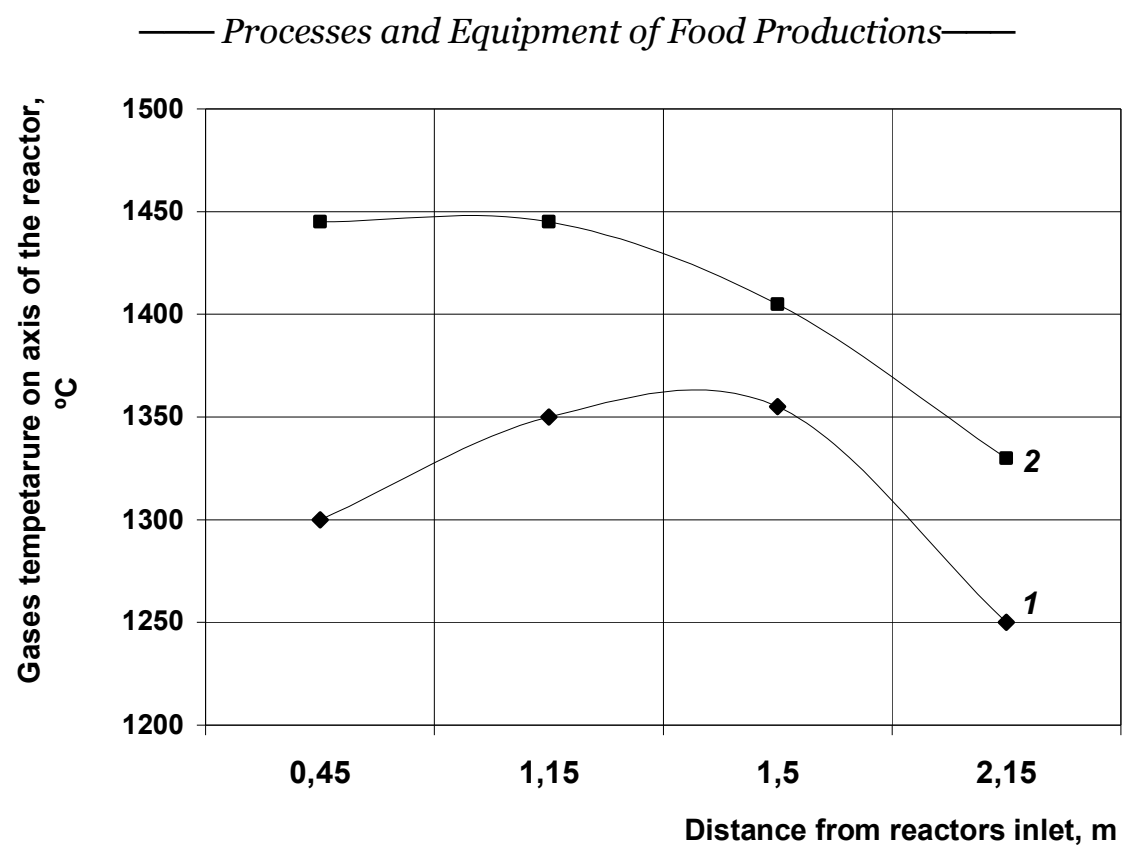

Figire 5. Temperature distribution in reactor and coal conversion degree comparison under its lighting by natural gas and sawdust: 1 - mode anthracite/gas $(93,8 \% / 6,2 \%)$, Xcoal $=60,8 \%$;

2 - mode anthracite/sawdust $(97,1 \% / 2,9 \%)$, Xcoal $=56,5 \%$.

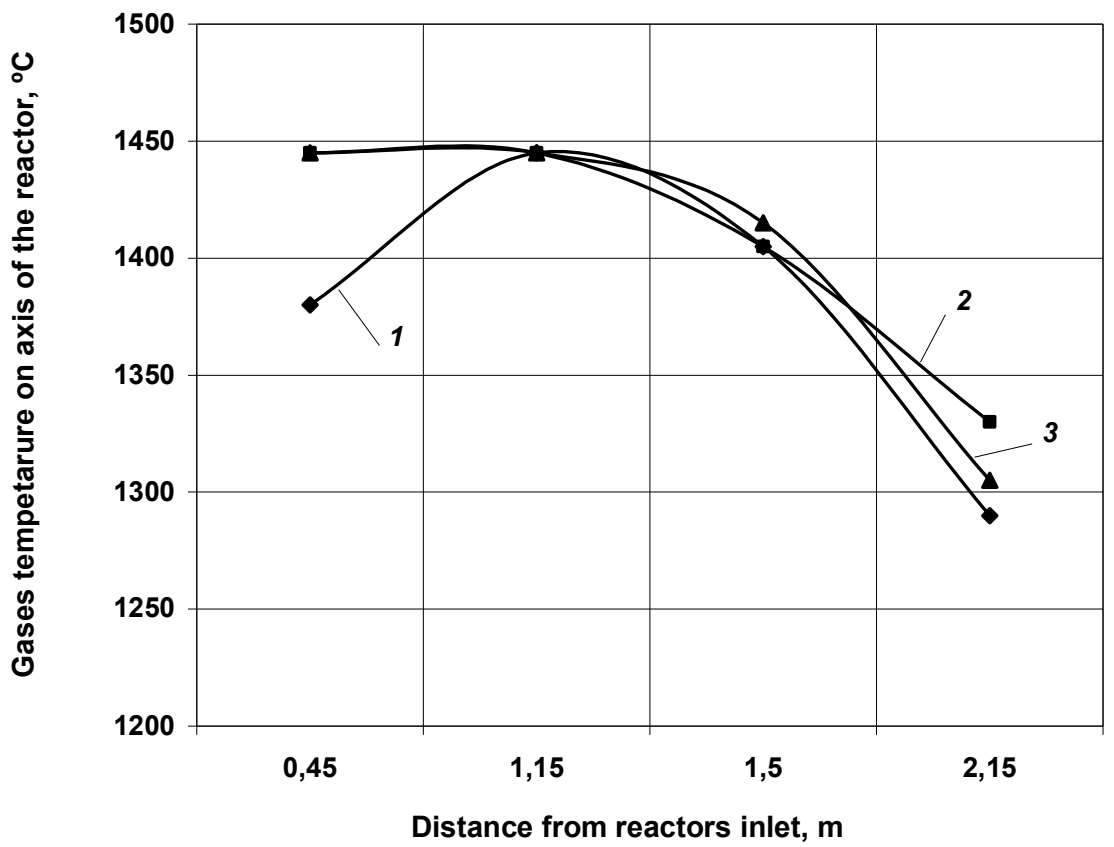

Figure 6. Dependence comparison of the sawdust conversion degree under- co-combustion with anthracite: 1 - sawdust share $2,9 \%$; Xcoal $=56,5 \%$; 2 - sawdust share $8,4 \%$ Xcoal $=75,9 \%$; 3 - sawdust share $14,3 \%$ Xcoal $=70,4 \%$. 
As per temperature measurement results in the reactor and coal carbon conversion degree under its lighting by the natural gas and co-combustion with sawdust, then the obtained results show that even under biomass supply at a rate of $2,9 \%$ by heat value it completely succeeded to refuse from the torch lighting by natural gas although coal conversion degree slightly decreased compared to gas lighting regime (see Figure 5). Herewith, the core torch temperature significantly increased. By increasing the supply of the biomass up to $8,4 \%$ by the heat value, the significant increase of the coal conversion degree is observed, as well as palpable extension of torch (Figure. 6) due to increase in time of the coke residue burn-out time of the biomass particles that can exceed the anthracite coke burn-out time. The further increase in biomass supply while maintaining the torch stability and high heat density of reactor volume leads to the carbon conversion degree reduction. This fact is connected with that highreactive fuel that is this case is sawdust rapidly consumes air oxygen in high temperature core zone thereby worsening the conditions of coal burn-out.

Based on the above-mentioned, on the basis of the co-combustion regimes' comparison under heat share variation that is brought by the biomass (Figure 6), the optimal thermal share of the biomass was determined that is about $10 \%$ (Figure 7 ). The supply of such biomass share in high-ash anthracite and biomass co-combustion regimes provides torch stabilization without gas lighting and highest degree of the coal carbon conversion.

The conducted studies confirmed the feasibility of efficient substitution of lighted natural gas by wood processing wastes in pulverized boiler units' furnaces which burn anthracite. The full natural gas substitution by biomass is accompanied by steady burning in the experiments. Upon this, the gas temperature increase in reactor is observed. The volatiles' shortage compensation in the anthracite due to sawdust is proven efficient measure to support the low-reactive coal burning, even in case of high-ash coal combustion.

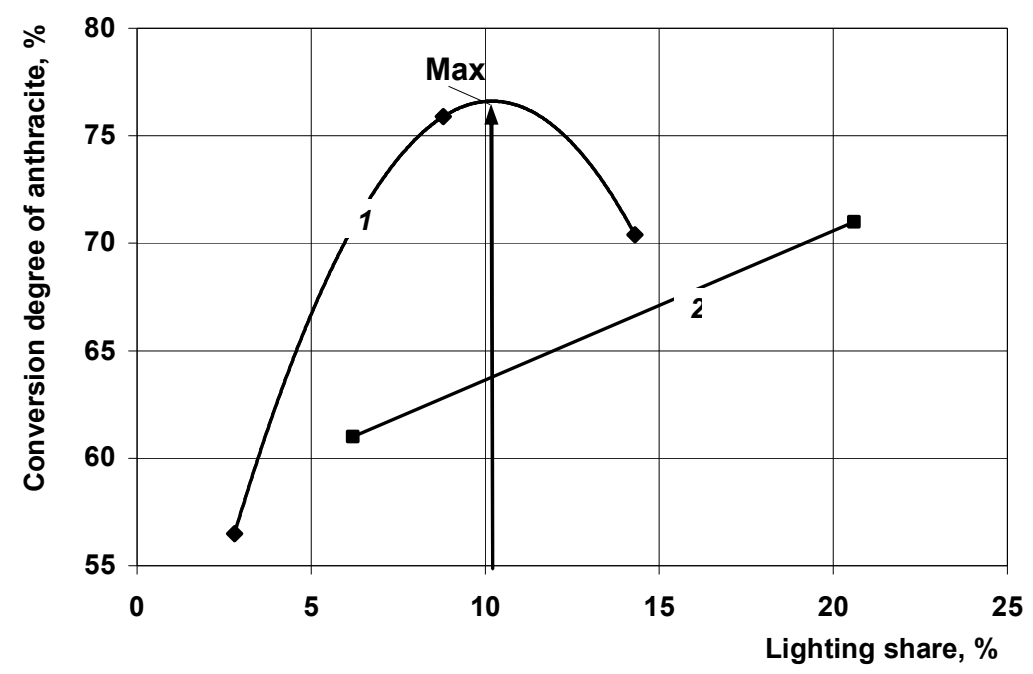

Figure 7. The dependence of the coal conversion degree from the natural gas and sawdust lighting:

1 - sawdust; 2 - natural gas; Max - the optimal thermal share of the biomass. 


\section{— Processes and Equipment of Food Productions -}

\section{Conclusions}

The co-combustion of pulverized domestic anthracite and wood in the unit VGP-100V has proven its technical realizability and a noticeable potential to significantly improve the quality of low-reactive anthracite combustion. In the event of unsatisfactory state of boiler units or supplies of high-ash coal at TPP's, wood is more efficient alternative to use natural gas to maintain anthracite burning stability.

The study of the carbon reaction rate dependence of wood coke with air oxygen from the temperature at unit RSK-1D indicates the presence of intra-kinetic burning regime in the temperature range of $390-560{ }^{\circ} \mathrm{C}$.

The analysis of thermogravimetric study results shows possible significant differencies in characteristics of solid biomass as separate types, as different samples of the same type. Therefore, unlike with coal in each case of the BCCC technology implementation, it is necessary to study biomass that is planned to burn.

Presented results can be used in calculations of the some stages co-combustion processes which take place in TPP's.

\section{References}

1. Dunaievska N., Zasiadko Ya., Shupik I., Shchudlo T. (2007), Ohliad tekhnolohii spilnoho spaliuvannia biomasy i vuhillia v pylovuhilnykh topkakh, Enerhotekhnolohyy y resursosberezhenye, 3, pp. 3-8.

2. (2016), Database of Biomass Cofiring initiatives, available at: http://www.ieabcc.nl

3. (2002), National Renewable Energy Laboratory (NREL), May 2002, NREL/TP-51032260, available at: http://www.nrel.gov/docs/fy02osti/32260.pdf

4. (2010), Lesley Sloss. Emissions from cofiring coal, biomass and sewage sludge (IEA Clean Coal Centre), available at: https://www.usea.org/sites/default/files/ 102010_Emissions\%20from\%20cofiring\%20coal\%2C\%20biomass\%20and\%20sewage $\% 20$ sludge_ccc175.pdf

5. Fernando R. (2005), Fuel for biomass cofiring, IEA Clean Coal Centre, pp.37

6. Zasiadko Ya.I., Myroshnyk M.M., Zasiadko P.Ya. (2012), Termohravimetrychni doslidzhennia buriakovoho zhomu, Tsukor Ukrainy, 2(74), pp. 29-32.

7. Matveichuk A. (2012), O tekhnologii sovmestnogo szhiganiia burogo uglia i solomy $\mathrm{v}$ topochnykh kamerakh s nepodvizhnym sloem, Vidnovliuvana energetika, 3(30), pp.79-83.

8. Maistrenko O., Dunaevska N., Zasiadko Ya., Bondzyk D., Shchudlo T., Vyfatniuk V. (2012), Tekhnolohiia ta palnyk dlia spaliuvannia biomasy yak dopomizhnoho palyva $\mathrm{v}$ fakelnykh kotloahrehatakh, Nauka ta innovatsii, 4, pp. 83-88.

9. Dunaevskaya N., Zasyad'ko Ya., Shchudlo T., Bestsennyy I., Bondzik D. (2009), Eksperimental'noe issledovanie protsessa sovmestnogo fakel'nogo szhiganiya antratsita $\mathrm{s}$ drevesnoy biomassoy, Energotekhnologii i resursosberezhenie, 3, pp. 10-17.

10. Guo J., Lua A. (2001), Kinetic Study on Pyrolytic Process of Oil-Palm Solid Waste Using Two-Step Consecutive Reaction Model, J. Biomass and Bioenergy, 20, pp. 223233

11. Gil M., Casal D., Pevida C., Pis J., Rubiera F. (2010),. Thermal behaviour and kinetics of coal/biomass blends during co-combustion, Bioresource Technology, 101(14), pp. 56015608 
12. Sema Yurdakul Yorulmaz, Aysel T. Atimtay (2009), Investigation of combustion kinetics of treated and untreated waste wood samples with thermogravimetric analysis, Fuel Processing Technology, 90, pp. 939-946

13. Yu Zhaosheng, Ma Xiaoqian, Liu Ao (2008), Kinetic studies on catalytic combustion of rice and wheat straw under air- and oxygen-enriched atmospheres, by using thermogravimetric analysis, J. Biomass and bioenergy, 32, pp.1046-1055

14. (2013), Maria Inez G. de Miranda, Clara I. D. Bica*, Sonia M. B. Nachtigall, N. Rehman, Simone M. L. Rosa, Thermal decomposition of soybean hull cellulose: a kinetic study, $12^{\circ}$ Congresso Brasileiro de Polimeros (12 $\left.{ }^{\circ} \mathrm{CBPol}\right)$, September 22-26: Proceedings, available at:

https://www.lume.ufrgs.br/bitstream/handle/10183/81824/000901361.pdf?sequence=1 